\title{
Is Couple and Relationship Education Effective for Lower Income Participants? A Meta-Analytic Study
}

\author{
Alan J. Hawkins \\ Brigham Young University - Provo, hawkinsa@byu.edu \\ Sage E. Erickson \\ Brigham Young University - Provo
}

Follow this and additional works at: https://scholarsarchive.byu.edu/facpub

Part of the Other Social and Behavioral Sciences Commons

\section{Original Publication Citation}

Hawkins, A. J., \& Erickson, S. E. (2015). Is couple and relationship education effective for lower income participants? A meta-analytic study. Journal of Family Psychology, 29, 59-68.

\section{BYU ScholarsArchive Citation}

Hawkins, Alan J. and Erickson, Sage E., "Is Couple and Relationship Education Effective for Lower Income Participants? A Meta-Analytic Study" (2014). Faculty Publications. 4244.

https://scholarsarchive.byu.edu/facpub/4244

This Peer-Reviewed Article is brought to you for free and open access by BYU ScholarsArchive. It has been accepted for inclusion in Faculty Publications by an authorized administrator of BYU ScholarsArchive. For more information, please contact ellen_amatangelo@byu.edu. 


\title{
Is Couple and Relationship Education Effective for Lower Income Participants? A Meta-Analytic Study
}

\author{
Alan J. Hawkins and Sage E. Erickson \\ Brigham Young University
}

\begin{abstract}
The negative effects of family instability on children and adults have captured the attention of legislators and policymakers wondering if something could be done to help at-risk couples form and sustain healthy relationships and marriages. For a decade now, public funds have supported grants to provide couple and relationship education (CRE) to lower income individuals and couples. This meta-analytic study reviewed 38 studies (with 47 independent samples) assessing the effectiveness of CRE for lower income couples (defined as more than two-thirds of the sample below twice the poverty level) in an attempt to inform current policy debates. Overall effect sizes for control-group studies suggest that CRE for diverse, lower income couples has small, positive relationship effects (overall $d=.061$ ), especially on self-reports of relationship quality, communication, and aggression. There were somewhat stronger effects for studies with more married couples $(d=.091)$, mostly "near-poor" (vs. poor) participants $(d=.074)$, and more (vs. fewer) participants in relationship distress $(d=.072)$. In comparison to the effect sizes for control-group studies, the effects of one-group/prepost studies were larger (overall $d=.352$ ). Practitioners will need to continue to innovate curriculum design and pedagogy, improve other programmatic elements, and find ways to increase participant engagement to achieve greater success with the limited public funds that support CRE.
\end{abstract}

Keywords: couple and relationship education, family policy, low-income couples, meta-analysis, program evaluation

Supplemental materials: http://dx.doi.org/10.1037/fam0000045.supp

Numerous scholars have documented the high rates of family instability in the United States and the challenges they present to children and adults (Cherlin, 2009; McLanahan \& Beck, 2010). More than half of children born to the least educated and to women under 30 are born to nonmarital unions (Wildsmith, StewardStreng, \& Manlove, 2011). New analyses put the current divorce rate at nearly $50 \%$ for first marriages, and over the past 30 years that rate has doubled for those over age 35 (Kennedy \& Ruggles, 2014). Rates of family stability are not uniform, however; less educated and lower income couples experience the highest rates of marital and nonmarital union dissolution (Cherlin, 2009).

The negative effects of family instability on children have captured the attention of U.S. legislators and policymakers wondering if something could be done to help at-risk couples form and sustain healthy relationships and enduring marriages. Of course, much social and economic policy indirectly addresses family instability; for instance, better job prospects, greater educational opportunities, and help with substance abuse facilitate family stability (Haskins \& Sawhill, 2009). However, beginning in the late 1990s, government officials began exploring whether more

This article was published Online First November 24, 2014.

Alan J. Hawkins and Sage E. Erickson, School of Family Life, Brigham Young University.

Correspondence concerning this article should be addressed to Alan J. Hawkins, School of Family Life, Brigham Young University, 2092-D JFSB, Provo, UT 84602. E-mail: hawkinsa@byu.edu direct support might help. Some speculated that public funding for couple and relationship education (CRE) could help more disadvantaged couples form and sustain healthy relationships, increase child well-being, and reduce poverty. Researchers have conducted a handful of recent meta-analytic studies that support the potential effectiveness of CRE (Blanchard, Hawkins, Baldwin, \& Fawcett, 2009; Fawcett, Hawkins, Blanchard, \& Carroll, 2010; Hawkins, Blanchard, Baldwin, \& Fawcett, 2008; Hawkins, Stanley, Blanchard, \& Albright, 2012; Lucier-Greer \& Adler-Baeder, 2012; McAllister, Duncan, \& Hawkins, 2012; Pinquart \& Teubert, 2010). However, nearly all of the studies examined in these systematic reviews have been focused on well-educated, middle-income samples common to these programs, so these reviews cannot address the social policy utility of CRE for more disadvantaged populations.

Over the past decade, U.S. federal and state policies have provided more than $\$ 900$ million to support delivery of free or low-cost CRE services targeted primarily to lower income populations by a wide array of community organizations (Hawkins \& VanDenBerghe, 2014). Public policies in the United Kingdom and Australia also have supported CRE programming for couples with the intent to strengthen families and improve child well-being (Cowan \& Cowan, 2014; Halford \& Van Acker, 2012). Efforts in the United States, however, have been more extensive than other countries, perhaps because of comparatively high rates of divorce and income inequality. Substantial funding in the United States has been provided by direct congressional legislation alongside Temporary Assistance to Needy Families (TANF) reauthorization in- 
cluded in the 2005 Deficit Reduction Act. The TANF program once again is due for congressional reauthorization.

Is public policy that supports CRE for lower income couples working? One correlational study found evidence that variation in CRE funding state-to-state and year-to-year was associated with small but positive demographic outcomes (Hawkins, Amato, \& Kinghorn, 2013). However, a more direct test of this question comes from experimental studies of CRE programs targeted to lower income couples. Of course, it is important to understand that low-income levels are strongly correlated with a set of factors that make healthy relationships harder to form and sustain, such as mental health issues, substance abuse, underemployment, and others. Accordingly, there has been significant debate about the merits and utility of CRE as a policy tool to increase family stability and children's well-being (see Hawkins \& VanDenBerghe, 2014, for a summary). Some scholars argue that funds are misspent on programs to help strengthen couple relationships; funds would be more useful if they were used to help fix the social and economic problems that make forming and sustaining healthy relationships and marriages harder for lower income individuals. Given these difficult challenges, some scholars argue that merely providing knowledge and skills for healthy relationships is unlikely to change the trajectory of their relationships (Johnson, 2012; Trail \& Karney, 2012). Others argue that given added challenges facing lower income couples, it is incumbent on a just society to add healthy relationship education to other policy efforts to help disadvantaged individuals deal with unique stresses on their relationships. Some (on both the left and right) argue that government involvement in such personal matters as family formation and stability is beyond the appropriate scope of government. Still others are simply pragmatically pessimistic about the ability of brief educational interventions to make a difference in the stressful personal lives of disadvantaged individuals with more complex family relationships.

In the midst of these debates, data now are emerging to shed light on the effectiveness of CRE for lower income couples. Public funds were used to adapt and disseminate programs through demonstration grants to community organizations. Substantial numbers of lower income individuals and couples have participated in these programs and say they are helpful (Hawkins \& Ooms, 2012). Now a first generation of evaluation studies of CRE programs has examined whether these programs are strengthening lower income couple relationships.

So far, the evidence of CRE effectiveness for lower income couples is mixed. Some recent rigorous studies suggest the possibility that CRE can have small to moderate effects on couple relationship outcomes for disadvantaged couples (Cowan, Cowan, Pruett, Pruett, \& Wong, 2009; Lundquist et al., 2014; Stanley et al., 2014). Furthermore, a number of less rigorous (one-group/prepost) studies have found modest, positive effects for such couples (e.g., Antle et al., 2013; Owen, Quirk, Bergen, Inch, \& France, 2012; Rauer et al., 2014). Moreover, there is some early evidence from these and other studies that the effects of CRE may be even stronger for more socioeconomically disadvantaged participants (Amato, 2014; Rauer et al., 2014; Stanley et al., 2014; Williamson, Trail, Bradbury, \& Karney, 2014). In addition, there is some evidence emerging that minority participants in CRE may gain greater benefit than nonminority participants (Hawkins et al., 2013).
Nevertheless, a rigorous, large, multisite evaluation of the Building Strong Families (BSF) program for unmarried, lower income couples found few positive, long-term impacts, and even some potential negative impacts (Wood, Moore, Clarkwest, \& Killewald, 2014). The BSF study differed from most other studies because it had lower participation rates in the interventions and it targeted unmarried couples, whereas most of the research finding positive impacts examined effects on (mostly) married couples. For instance, a parallel, large, multisite evaluation of the Supporting Healthy Marriage (SHM) program found small but statistically significant increases at 2 years postprogram on measures of marital functioning and psychological well-being, and decreases in psychological abuse (Lundquist et al., 2014).

The BSF and SHM results suggest that marital status might moderate the effects of CRE for lower income couples (although there were other important differences between the BSF and SHM programs). Perhaps married couples benefit more from CRE than unmarried couples because they have made more commitment to their union and are more motivated to improve it. Furthermore, married couples in these studies likely have been together for a longer period of time than unmarried couples. Couples together for a longer period of time may be better prepared to incorporate new skills and knowledge into their behavioral and cognitive repertoires than couples together for shorter durations. Length of the couple relationship, then, also may be an important moderator to examine. Additionally, married couples may be more likely to engage fully in CRE programs, so program participation will be an important moderator to explore, as well. In addition, poverty status (poor vs. near poor) could moderate program effects. The poorest couples may simply be overwhelmed and less able to take advantage of new skills and knowledge, as some scholars have hypothesized (Johnson, 2012). Similarly, the poorest couples could be more distressed entering the program. Accordingly, poverty status and relationship distress should be examined as moderators of program effects.

The purpose of this meta-analytic study, then, is to rigorously review the emerging program-evaluation evidence addressing the effectiveness of CRE targeted to lower income individuals and couples. Given the growing body of recent studies and the current and coming policy debates, the time has come for a thorough assessment of the effectiveness of CRE programs for lower income couples.

\section{Method}

\section{Search Procedure and Inclusion Criteria}

To find all relevant studies, both published and unpublished, we conducted an extensive search for all CRE evaluation studies. Our primary inclusion criteria were: (a) the study had to be an empirical evaluation of a CRE program, with data to code an effect size, and (b) the study had to have a predominantly lower income sample. A handful of studies of youth/young adult relationship literacy programs were excluded because the outcomes measured in these programs are substantially different from couple-oriented programs. Some curricula are designed to reach both couple participants and single participants (many of whom are in relationships but attending alone); we included studies of these programs. "Lower income" was defined as less than twice the official U.S. 
poverty level for the year of the study, a common operationalization that includes the poor as well as the "near poor," who are at significant risk for falling below the official poverty line. (The average family size of the study's sample also was used to determine poverty status.) "Predominantly lower income" was operationalized as at least two-thirds of the sample was lower income. (Most of the included studies had only lower income participants.) We examined studies with control-group designs as well as prepost studies (with no control group), although these two groups of studies were analyzed separately.

We searched electronic databases (PyscINFO; Family \& Society Studies Worldwide; Dissertation Abstracts Online; Proquest) for studies. We searched reference lists of recent meta-analytic studies, as well. We also contacted active researchers in the field for in-press work, including social policy research organizations that have conducted major evaluation studies of CRE programs. In addition, we contacted numerous program providers with ACF grants to deliver CRE to lower income populations or explored their Web sites to see if they had published or unpublished evaluation studies on their programs. Specifically, we searched for grantees that collected outcome data from participants (not just demographic, usage, and formative evaluation data). We were not able to contact all ACF grantees (some grants expired in 2011), so our meta-analysis is likely missing a few in-house, unpublished evaluations. (These missing studies would all be one-group/pre- post studies. ACF grants were given to explore the potential of CRE; grantees had limited funds for rigorous outcome evaluation work.)

Overall, we identified 107 studies for further careful inspection. All CRE studies with lower income samples were reported after 2000. We found no eligible studies with non-U.S. samples. Sixtytwo studies were excluded because they did not focus on lower income samples or focused on youth relationship education instead of adult CRE. Additionally, a couple of one-group/prepost studies had participant attrition rates higher than 50\%; we excluded these studies because of the high risk that the program effects would be biased. Some studies did not supply adequate data to compute effect sizes. In these instances, we tried to contact researchers and some responded to our inquiries for more data, so we were able to include those studies. However, seven studies were dropped for lack of effect-size data. All eligible studies were available in public technical reports or peer-reviewed journals; we found no unpublished. As a result of these decisions, we included 38 studies in our analyses that yielded 47 independent samples. Figure 1 summarizes these inclusion/exclusion decisions.

There were 22 studies with a control-group design. A large proportion of these studies came from two large-scale, government-funded studies, BSF and SHM. However, these studies each included eight independent sites. Because these sites often had different program and sample features, we disaggregated the

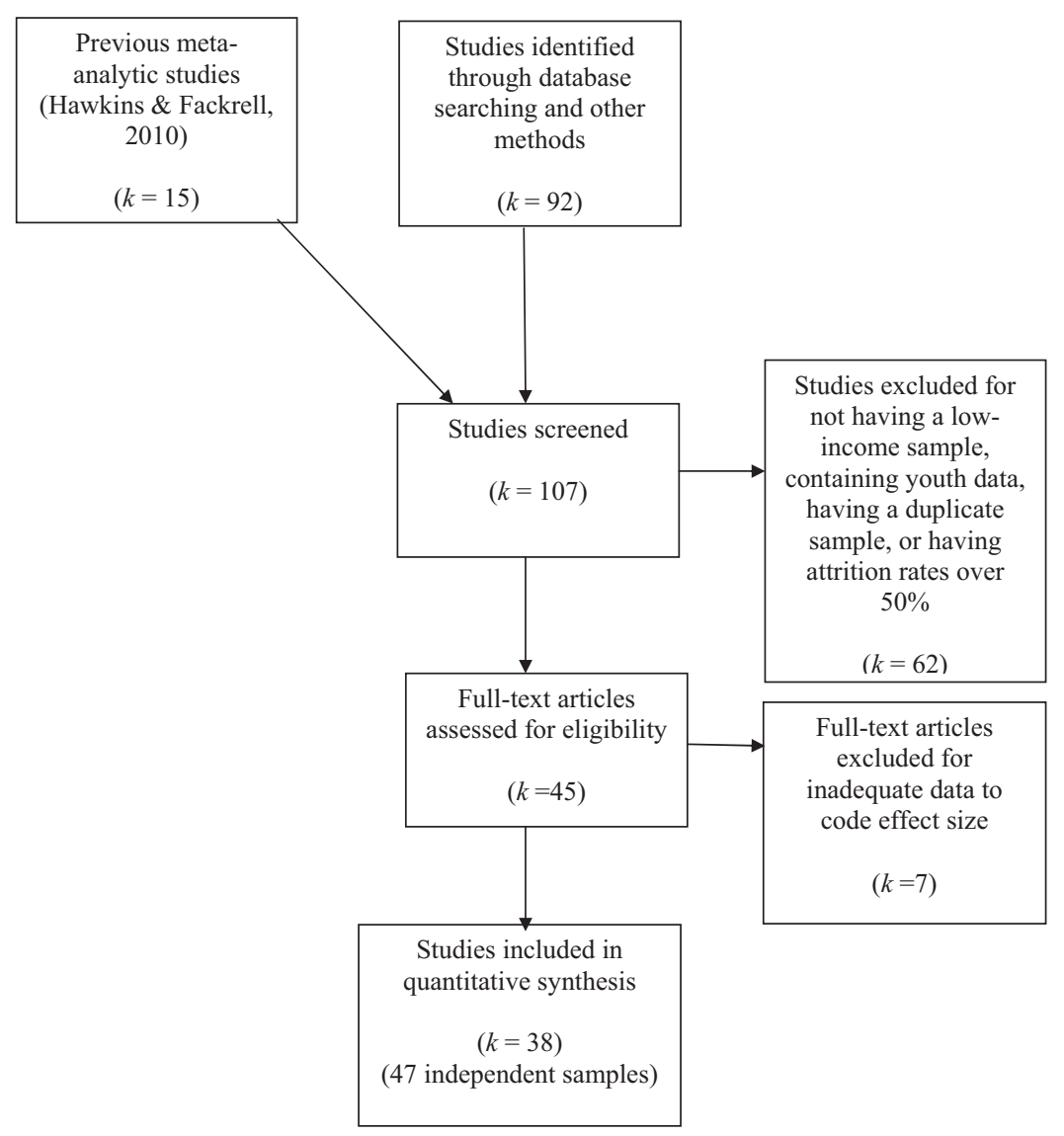

Figure 1. Flowchart of inclusion/exclusion decisions. 
sites and coded each local program separately with data available in technical reports. (The levels of sample attrition for the BSFHouston site at the 36-month follow-up were too high to meet the BSF study's standards for an acceptable level of risk of bias in estimating program impacts. Therefore, researchers did not report the 36-month results for the Houston site.) Accordingly, 15 of the 22 control-group studies came from these two reports. We acknowledge upfront that the BSF and SHM studies will numerically dominate this planned meta-analysis, and nonsignificant effects of the BSF study and significant-but-small effects of the SHM study suggest that the overall effect of CRE with lower income participants will be small or zero, at least for control-group studies. Nevertheless, given the relevance of this study to current policy considerations, we believe these analyses are warranted.

We also included 16 one-group/prepost studies. Although these studies cannot provide an unbiased estimate of program impacts because of lack of a control group, we included them in a separate analysis. Our justification for this is as follows: Reflecting the most rigorous standards of research, most of the true experimental studies used intent-to-treat analyses, measuring the impact of the educational intervention by comparing all participants randomly assigned to the treatment group-regardless of actual program involvement - to all participants assigned to the control groupregardless of other available treatments they may have sought on their own. Intent-to-treat analyses yield unbiased estimates of what the impact of offering an intervention would be in a population, accounting for program nonparticipation. In contrast, none of the prepost studies used intent-to-treat analyses, which are uncommon in fieldwork studies. That is, only the scores of those treatmentgroup subjects who participated in the intervention and contributed pre- and posttest assessments are used in analyses to compute an effect. This yields an estimate of the effect of the intervention on the treated, or in other words, an estimate of what the intervention effect is on those individuals who participate adequately in the intervention. This also is important information for practitioners to know about their interventions. Accordingly, we decided to examine effects of both control-group and one-group/prepost designs because they each have potentially valuable information.

Among the one-group/prepost studies, there were a number of reports produced from the same programs, often with overlapping samples. In these cases, we carefully examined the reports and contacted the researchers with questions to make sure that samples were not overlapping, thus avoiding problems of statistical dependence and excessive weighting of particular samples. In some instances, researchers provided us with updated, overall-project data that we used rather than the overlapping subsets in multiple reports, so the data in the reports were not the data we used to compute effects. Moreover, three study reports had independent samples yielding independent effect sizes. As a result, although there were 16 prepost studies, there were 25 independent samples that contributed to the computation of overall prepost effect sizes. (A summary table with all study reports used in the meta-analysis and corresponding aggregate effect sizes is available on the journal's Web site.)

\section{Coding Procedure and Moderators}

We coded effect sizes for commonly reported measures such as relationship satisfaction/quality and stability, commitment, com- munication and conflict-resolution, physical and psychological aggression, and coparenting quality. Our coding team consisted of one Ph.D. researcher and one M.S. student trained in meta-analysis (study authors), as well as a third trained undergraduate student. Two coders would code all the studies independently then come to a consensus about any conflicting items by further consulting the report. The Ph.D. researcher checked all effect-size coding. We coded all effect sizes in the appropriate direction, such that when they were combined they would consistently indicate greater positivity in the relationship. We also coded various moderators that potentially could explain heterogeneity in the distribution of effect sizes. These moderators included study design characteristics (e.g., experimental, quasi-experimental, and one-group/prepost), program characteristics (e.g., intended dosage, program participation levels), and sample characteristics (e.g., income, education, marital status, and relationship distress).

\section{Effect Size Computation}

We conducted separate analyses for control-group studies and one-group/prepost studies. In preliminary analyses, we tested for differences between true experimental $(k=19)$ and quasiexperimental (randomization not assured, $k=3$ ) studies for study outcomes but found no significant differences, although the effect sizes for the three quasi-experimental studies were somewhat larger. To aid in a more parsimonious presentation of the results, we combined the true- and quasi-experimental studies for all analyses. We coded the latest follow-up effects available in the study. Nearly all control-group studies had follow-up assessments of 1 to 3 years, while most prepost studies had only immediate postprogram or short-term follow-up assessments.

For control-group studies, we calculated the standardized mean difference. For one-group/prepost studies, we calculated the standardized mean change. (We used Biostat's Comprehensive Meta Analysis II to perform these calculations.) Effect sizes were weighted by the inverse variance. We used random effects estimates in our analyses that allow for the possibility that variation in the distribution of effect sizes is produced not only by sampling error but also by program differences, intervention methods, and other factors (Lipsey \& Wilson, 2001). Random effects estimates are more readily generalizable to the field, with its large variety of CRE programs and participants. Because most studies had multiple outcomes, we aggregated effect sizes to the study level. This is required so studies that contribute more effect sizes are not disproportionately weighted in the overall effect size. Effect size heterogeneity was examined with $Q$-tests for heterogeneity and the $I^{2}$ statistic.

When coding the one group/prepost studies, a correlation between the pretest and the posttest is required but often unreported. In these instances, we used an average correlation of .50. This assumed correlation is generally close to the actual average correlations and does not bias the overall effect size (Nowak \& Heinrichs, 2008). (Sensitivity analyses using a higher correlation of .60 did not substantially alter the results.)

\section{Study Participants Summary}

Nearly all control-group studies had significant diversity in their samples (more than 50\% racial/ethnic minorities). Most studies 
had samples with lower levels of education (high school degree or lower), with only a small percentage indicating that they had some college education. About one-half of the studies had samples with moderate numbers of distressed couples at program entry $(11 \%$ to $25 \%$ ) and the other half had samples with more distressed couples, including one-third with a majority distressed. (Studies reported distress as the percentage of individuals who said they recently thought their relationship was in trouble or those who were below a cutoff level on a standardized relationship quality measure.)

\section{Findings}

\section{Control-Group Studies}

For control-group studies, combining all the outcomes, we found a significant but small overall effect size of $d=.061$ ( $p<$ $.01, k=22$ ). (When the three quasi-experimental control-group studies were removed, the effect size dropped slightly to $d=.054$.) Looking at specific outcome variable categories, we found effect sizes were statistically significant for three of the five categories: relationship satisfaction/quality $(d=.067, p<.01, k=21)$, communication skills $(d=.063, p<.05, k=19)$, and relationship aggression $(d=.055, p<.01, k=10)$, but not significant for relationship stability $(d=-.002, k=16)$ and coparenting $(d=$ $.029, k=17$ ). There were no outliers that substantially distorted these effects. Trim and fill analyses did not reveal evidence of substantial bias from missing studies.

Moderator analyses. The heterogeneity in the distribution of effects was modest for the combined outcomes $\left(\mathrm{Q}=43.9, I^{2}=\right.$ $52 \%$ ) but enough to justify follow-up moderator analyses. Thus, we analyzed the effect sizes for several moderators that conceptually may account for the heterogeneity in the distribution of effect sizes: marital status, relationship length, poverty status, ethnic/racial diversity, relationship distress (at program entry), and participant engagement (average actual dosage of the intervention).

Studies with mostly married participants had a larger effect size $(d=.091, p<.001, k=13)$ than those with mostly unmarried participants $(d=-.016, n s, k=9)$, a difference that was statistically significant $(\mathrm{Q}=6.6, p<.05)$. The difference in marital status likely is reflected as well in a moderator variable that examined participants' relationship length (sample average $=0-5$ years vs. $6+$ years). Programs with participants in a relationship for longer periods of time had a larger effect size $(d=.139, p<$ $.05, k=6)$ than those together for a shorter period of time $(d=$ $.033, n s, k=11$ ), although this difference was statistically marginal $(\mathrm{Q}=2.9, p<.10)$. Nearly all control-group studies had samples with large proportions of African American and Hispanic participants, so this lack of variation prevented an adequate test of whether sample ethnicity/race was a potential moderator. Programs with the most participants below the federal poverty line $(67 \%+)$ showed no effect $(d=-.033, n s, k=7)$ whereas programs with more "near-poor" $(<66 \%$ below poverty) participants showed stronger but still small effects $(d=.074, p<.001$, $k=12)$, a difference that was significant $(\mathrm{Q}=8.5, p<.01)$. Programs with more participants in distressed relationships at program entry had stronger though small effects than programs with fewer participants in relationship distress (for $<25 \%$ distressed: $d=-.033, n s, k=7$; for $25 \%+$ distressed: $d=.072, p<$
$.001, k=8)$, a difference that also was significant $(\mathrm{Q}=8.1, p<$ $.01)$. Finally, the differences between programs with greater or lesser levels of participant engagement were nonsignificant $(\mathrm{Q}=$ 2.3, $n s$; for $<12 \mathrm{hr}: d=.071, n s, k=7$; for $12-18 \mathrm{hr}: d=.053$, $p<.01, k=9$; for $19+\mathrm{hr}: d=.102, p<.001, k=4)$.

\section{One-Group/Prepost Studies}

For one-group/prepost studies, combining all outcome variables, we found an overall significant, moderate effect size: $d=.352$ $(p<.001, k=25)$. Looking at specific outcome variable categories, we found effect sizes were significant for three of the five categories: relationship satisfaction/quality $(d=.362, p<.001$, $k=23)$, communication skills $(d=.453, p<.001, k=11)$, and coparenting $(d=.251, p<.001, k=10)$, but not significant for relationship stability $(d=.278, n s, k=11)$ and relationship aggression $(d=.023, n s, k=4)$. Because there was a greater chance that we did not find all fieldwork studies of CRE programs for lower income couples, especially those conducted by ACF grantees, we conducted trim and fill analyses to determine if potential missing studies were biasing the effect size. These analyses, suggested some possible bias in missing studies with stronger effects than the mean effect (trimmed $d=.492$ ). There were no outliers that substantially distorted these effects.

Moderator analyses. The heterogeneity in the distribution of effects was large for the combined outcomes $\left(\mathrm{Q}=764.7, I^{2}=\right.$ $96.9 \%$ ), suggesting the value of follow-up moderator analyses. Thus, we analyzed the effect sizes for a similar set of moderators to see if they accounted for heterogeneity in the distribution of effect sizes. In contrast to the control-group studies, prepost studies with mostly married participants $(d=.277, p<.001, k=11)$ did not differ significantly $(\mathrm{Q}=.65, n s)$ from those with mostly unmarried participants $(d=.394, p<.01, k=14)$. Similarly, the difference between studies with participants together for a longer period of time $(6+$ years: $d=.360, p<.001, k=5)$ and studies with participants together for a shorter period of time ( $0-5$ years: $d=.223, n s, k=4)$ did not reach statistical significance $(\mathrm{Q}=.99$, $n s)$. However, similar to control-group studies, programs with the most participants below the federal poverty line $(67 \%+)$ showed no effect $(d=.061, n s, k=1)$ whereas programs with fewer participants below the poverty line $(<67 \%)$ showed stronger effects $(d=.285, p<.001, k=7)$, a difference that was significant $(\mathrm{Q}=5.8, p<.05)$. However, because of the small number of studies reporting these data, this finding should be treated cautiously. We were able to examine program participant ethnic/racial diversity as a moderator for prepost studies. We found that programs with greater proportions of non-White participants had stronger effects $(\mathrm{Q}=7.39, p<.05$; for $<25 \%$ : $d=.099, n s, k=$ 4 ; for $25 \%$ to $49 \%$ : $d=.232, p<.001, k=5$; for $50 \%+: d=$ $.450, p<.001 k=16$ ). There were an insufficient number of studies coded for distress at program entry to test for moderating effects. Finally, the differences between programs with greater and lesser levels of participant engagement were minimal and nonsignificant $(\mathrm{Q}=.37, n s$; for $<12 \mathrm{hr}$ : $d=.267, p<.001, k=14$; for 12-18 hr: $d=.174, n s, k=3$; for $19+\mathrm{hr}: k=0$ ).

\section{Discussion}

Our meta-analytic review of 22 control-group studies evaluating the effects of CRE targeted to lower income couples was numer- 
ically dominated by the BSF-site studies, with nonsignificant effects, and the SHM-site studies, with significant but small effects. Nevertheless, the overall results found a small but statistically significant effect $\left(d_{\text {all }}=.061\right)$ driven by increases in reported marital satisfaction/quality $(d=.067)$ and communication skills $(d=.063)$ and a decrease in relationship aggression $(d=.055)$. An asset of meta-analysis is its ability to detect small effect sizes when separate studies are aggregated, even when some of those separate studies have nonsignificant effects. In this case, it provides a more sensitive test that combines the large BSF and SHM studies with other relevant control-group studies. There was no evidence of change in coparenting and relationship stability. Only two studies to date have found positive effects for stability: the BSF Oklahoma City site (20\% greater chance of unmarried couples being together continuously for 3 years) and the Army Strong Bonds program (married couples about half as likely to be divorced after 2 years; Stanley et al., 2014). In contrast, one of the BSF sites (Florida) showed small, negative effects on stability.

The meaning of the stability outcome measure, however, is more ambiguous than the other outcomes because not all instability is negative. That is, one of the intended goals of CRE is to educate individuals about both healthy and unhealthy relationships. Some participants may discern that their relationship is unhealthy or dangerous and initiate a "positive break-up." (Omitting relationship stability from the aggregate outcome only increases the overall effect size slightly to $d=.066$.) Of course, some in unhealthy relationships may choose to stay together and participating in CRE possibly could encourage that choice even without improvement in relationship skills. Regardless, the lack of an overall positive stability effect in this meta-analysis is disappointing given the effects of family instability on children's wellbeing (Cherlin, 2009).

Our systematic review of rigorously evaluated CRE programs suggest they are only showing small impacts. Small effect sizes of this magnitude indicate only $52 \%$ to $53 \%$ of treatment-group participants are above the control-group mean as a result of the intervention. The small effects are weaker than those found in CRE studies with financially better-off participants. Those effects are generally (but not uniformly) between .20 to .70 (Blanchard et al., 2009; Fawcett et al., 2010; Hawkins et al., 2008; 2012; LucierGreer \& Adler-Baeder, 2012; McAllister, Duncan, \& Hawkins, 2012; Pinquart \& Teubert, 2010).

Why the smaller effects? One partial explanation may be methodological; note that nearly all the relationship outcome data used in this study were self-reported. Previous meta-analytic studies (Blanchard et al., 2009; Fawcett et al., 2010) found that effect sizes associated with observed outcome measures in CRE studies produced substantially larger effect sizes compared with self-report data, so the findings in these studies may underestimate effects. Another possible explanation is that in many of these studies there were low program-engagement rates, especially in the BSF study sites, in which, on average, only $60 \%$ of participants ever attended a class (and only $10 \%$ received a strong dose of the intervention). Although implementation evaluation studies have documented interest in CRE programs among lower income individuals and couples, and those who participate say they enjoy the programs and benefit from them (Hawkins \& Ooms, 2012), engaging participants for a strong dose of the intervention is a challenge. In recent years, program administrators have learned more about how to retain lower income participants by assisting with transportation and child care, as well as offering various incentives (Hawkins \& Ooms, 2012). Of course, these necessary efforts add considerable expense to the programs. Still, we suspect that program participation rates cannot be the full explanation for small effects, because even the control-group studies with admirable participation rates generally still had relatively small effects (between $d=.083$ to .109).

Accordingly, another possible explanation is that CRE simply is not as effective with lower income couples, either because the curricula are less relevant to the daily challenges they face or because everyday stresses and chronic relationship challenges of poorer Americans overwhelm the basic skills and knowledge they may gain, as some scholars have surmised (Edin \& Kefalas, 2005; Johnson, 2012; Trail \& Karney, 2012). Evidence to support this explanation comes from the fact that programs with the poorest participants did not show effects while programs with more "nearpoor" participants saw larger (but still small) effects. We urge some caution in interpreting this moderator effect because of a potential confound: The poorer samples in this moderator test were mostly from the BSF evaluation sites. However, we saw the same pattern of no effects for the poorest samples with a small set of prepost studies in our meta-analysis, lending support to a potential, real moderator effect. The stress and complexity of life for the poorest may provide rocky soil for healthy relationship knowledge and skills to take root; modest educational programs may not be enough to overcome these challenges. On the other hand, some studies (Amato, 2014; Rauer et al., 2014; Stanley et al., 2014; Williamson, Trail, Bradbury, \& Karney, 2014) have found larger effects for the most disadvantaged, at-risk participants in CRE. Perhaps closely integrating CRE services with other social services (e.g., employment, substance abuse) could prove fruitful, and in fact this approach is being emphasized by current U.S. policy efforts.

Regardless, we suspect that program designers and administrators will continue to face a steep learning curve as they work to improve the effectiveness of CRE programs for the mostdisadvantaged couples. Some CRE curricula have incorporated a focus on dealing with external life stressors and positive coping, in addition to relationship education. Furthermore, as some scholars suggest (Allen, 2012; Edin \& Kefalas, 2005), programs may need to take on both more basic issues - such as relationship commitment and how fathers matter to children's well-being — as well as more daunting issues-such as gender mistrust, infidelity, and substance abuse- to better help the most disadvantaged couples.

In addition, we found evidence that programs with higher proportions of couples in relationship distress at program entry experienced stronger effects from CRE programs. Perhaps these couples have more room for growth and more motivation for change than couples who take these programs to "tune up" their generally positive relationships. Many couples come to these interventions with relationship distress. That some are apparently benefitting from the programs is both encouraging and challenging. CRE is preventative education, not individualized therapy. These distressed couples may have limited access to relationship therapy services compared with financially better-off couples. Hence, CRE programs may provide a valuable service to help distressed, lower income couples who want to strengthen their relationships. However, program administrators may need to boost the effects of the 
curricula with some individualized help through, for instance, personalized home visiting instruction or regular booster sessions to refresh program learning. SHM programs, which found somewhat stronger effects, offered regular booster sessions. Some program administrators with the capability to offer brief therapeutic services in conjunction with CRE have expressed interest in doing so for distressed couples. Current policy does not allow funds for CRE to be used for therapy. There is debate, however, about the merits of this approach, with concern expressed for the quality of therapy likely to be provided and whether it will drain resources away from educational services.

Our meta-analysis suggests that marital status may be a significant moderator of CRE effects for lower income couples. In control-group studies (but not in prepost studies) CRE programs with unmarried couples showed little evidence of effects, whereas those for married couples showed consistent significant positive effects, albeit small ones, even when assessed several years after the program $\left(d_{\text {all }}=.091\right)$. However, again some caution is needed in interpreting this possible moderator effect. Almost all studies with unmarried samples came from the BSF multisite evaluation. This was the first large-scale program for lower income couples to be funded and tested; hence the learning curve was steep. The studies associated with BSF may be different, not just because participants were unmarried, but also because BSF was the first program of its kind and may have struggled more with implementation and other programmatic challenges. Furthermore, BSF couples were in shorter-term relationships than couples in the other studies and had smaller dosages of the intervention.

Nevertheless, with these cautions in mind, we speculate on why there could be a difference in the effectiveness of CRE programs based on participant marital status. One possible explanation is that CRE is effective primarily in the context of a strong commitment and orientation to the future, which is more likely among married couples. Without a strong commitment, relationship development is undermined (Stanley, Rhoades, \& Whitton, 2010) and the motivation to make use of knowledge and skills gained may be weaker. Alternatively, CRE models may be based more on married couples and what we know about them and their challenges; the content of CRE may not be as relevant to relationship issues of unmarried couples. Rhoades and her colleagues (Rhoades, Stanley, \& Markman, 2012) suggest that cohabiting couples face a double dose of challenges - dating-couple issues (e.g., commitment, time together) as well as married couple issues (e.g., household labor, parenting) — so the content of some CRE programs may need to be revised to be more relevant to unmarried couples.

We did not find evidence for a dosage-response effect. This contrasts with other meta-analytic studies of CRE programs with more advantaged participants, which found evidence of stronger effects for moderate dosage programs over lower dosage programs (Hawkins et al., 2008; 2012; Pinquart \& Teubert, 2010) but is consistent with one meta-analytic study focused specifically on premarital education (Fawcett et al., 2010). Conceptually, a greater dosage would support more learning and practice of relationship skills. Why the absence of a dosage effect for lower income couples? It may be that for these couples, the active ingredient of the intervention is primarily the decision simply to work on strengthening the relationship. Perhaps even lower dosages $(<12$ hr) are sufficient to demonstrate this commitment to and hope for the relationship that can help some couples. However, before recommending that policy prioritize briefer interventions, we must acknowledge that the lack of a correlation between dosage and outcomes confounds several possible effects: (a) the worst functioning couples drop out early; (b) the best functioning couples drop out early (because they don't need the intervention); (c) the worst functioning couples receive a full dosage but still are not helped; and (d) the couples who get the highest dosage, in fact, benefit most. The mixture of these effects may mask a dosageresponse effect. To disentangle these effects, studies are needed that assign participants to different dosage conditions.

When looking at one-group/prepost studies, effect sizes were larger $\left(d_{\text {all }}=.352^{* * * *}\right)$ than they were for control-group studies, and interestingly, the effects were strongest for studies with higher proportions of non-White participants in the program, a finding consistent with some other program evaluation studies (see Hawkins et al., 2013). The overall effects for prepost studies were driven by significant increases in reported communication skills $(d=$ $.459)$, marital satisfaction/quality $(d=.362)$, and cooperative coparenting $(d=.251)$. An effect size of $d=.40$ indicates that $66 \%$ of participants at posttest after the intervention were above the pretest group mean. The effect size for relationship stability ( $d=.278, n s, k=11$ ) was not significant but it was in the positive direction. There was no effect for relationship aggression, which contrasts with the small, positive effect we found in control-group studies.

Why was there a difference in effect-size magnitude for controlgroup and one-group/prepost studies? One explanation, of course, is that prepost studies cannot control for threats to internal validity and hence overestimate true effects. Meta-analytic studies of CRE interventions, however, do not provide strong evidence that prepost designs consistently produce larger effects; about half of the direct comparisons show larger effects for prepost effect sizes, but half show roughly equal or smaller effect sizes (see Blanchard et al., 2009; Fawcett et al., 2010; Hawkins et al., 2012; Lucier-Greer \& Adler-Baeder, 2012). Another possible explanation for the difference in magnitude between control-group and prepost studies is that control-group studies consistently (19 of 22) included longer term follow-up effects, usually 1-3 years, whereas most prepost studies (23 of 25 ) included only immediate postintervention effects. Perhaps prepost studies are not accounting for potential deterioration in effects over time. Again, however, recent CRE meta-analytic studies have not shown much evidence of deteriorating effects (see Blanchard et al., 2009; Fawcett et al., 2010; Hawkins et al., 2008; 2012; Pinquart \& Teubert, 2010).

We think a likely contributor to the substantial differences in effects between control-group studies and prepost studies is how effects were calculated in these studies. Most control-group studies (77\%) used intent-to-treat (ITT) analyses while all prepost studies used treatment-on-the-treated (TOT) analyses. Accordingly, the control-group studies, by including responses of those assigned to the treatment group but who did not participate in the intervention (program no-shows), were providing an estimate of the impact of offering CRE to an interested population of lower income couples. In contrast, prepost studies were providing an estimate of the effect of CRE programs on those who participated in the intervention (and completed a posttest, although some may not have received a full dose). When program attrition is high (and especially when those not benefitting from the program disproportionately drop out), then studies using ITT analyses will provide less biased and 
smaller estimates of effect sizes compared with TOT analyses (Orr, 1999). One is an estimate of the expected impact of a program on a population of those who express interest in the program (but many may not actually have participated), whereas the other is an estimate of the effect on those individuals who engage in the intervention. Both estimates are valuable. The conservative estimate provides policymakers with reason to be cautious about claims that CRE interventions in their current form will have a large impact on lower income couples when offered in their communities. More important, it can also be a signal that current interventions need to improve considerably to produce impacts worthy of long-term public support. The liberal estimate can inform practitioners that their interventions are helping lower income couples who invest in the programs, but signals that more efforts are needed to improve program engagement to achieve those positive effects for more people. Likewise, it can signal policymakers that with improvements in CRE programs, especially in their ability to engage participants, stronger effects would be expected.

Evidence to support this explanation for the difference between control-group and prepost studies comes from an analysis examining how type of analysis moderated the effects for control-group studies. Five control-group studies used TOT analyses and the effect for those studies on the aggregate outcome was $d=.383$ $(p<.01)$, a figure similar to that for prepost studies $(d=.352)$, whereas the effect for studies that used ITT analyses was small $d=.046(p<.01, k=17)$, a difference that was statistically significant $(\mathrm{Q}=7.4, p<.01)$.

\section{Conclusion}

Debates about the merits of continuing support for CRE to help lower income families have been dominated recently by reference to the BSF and SHM studies and their small or nonsignificant findings. These were the first attempts at large-scale roll-outs of CRE programs for lower income couples and much has been learned from them that may improve the potential for future program effects. Although these studies unquestionably were methodologically strong, scholars still have pointed out limitations, including measurement issues, no assessment of change, the fidelity and quality of program delivery, and other points (Halford \& Bodenmann, 2013). Our meta-analysis helps to broaden the empirical basis for this debate. The results of our meta-analysis suggest some basis for hope but a strong need for improvement. We found statistically significant, albeit small effects for CRE. Small effects are not irrelevant, and in the policy world, they are common and may even be cost-effective if the problems addressed create large government costs (Gueron \& Ralston, 2013). Still, practitioners clearly need to continue to innovate curriculum design and pedagogy to achieve greater success with the public funds that support CRE. This is no small task given that a substantial proportion of participants come to these programs with high levels of relationship distress and life stresses. On the other hand, it also means that they probably come highly motivated to learn and make changes. Unfortunately, there was not one program with an especially strong long-term effect that could point to a potential model program.

We have made a few suggestions for potential program improvements in our discussion so far of study findings. Our final suggestion, however, may be the most straightforward, immediate, and feasible improvement likely to strengthen effect: find innovative ways to increase program engagement of more participants. Recall the high levels of participant nonengagement evident in many of these studies; that is, many sign up but never show up. If commitment to many weeks and hours of intervention generally associated with the intensive programs found in the control-group studies depresses participant engagement-a reasonable assumption, especially for families under significant, temporal stressesthen reducing program dosage may be the most straightforward way to increase engagement. Recall also that we did not find a dosage effect, so positive program effects may be achievable with less intensive interventions. If this is the case, it would substantially lower the costs of supporting these programs and improve any cost-benefit policy analyses. A sustainable cost is an important element for building long-term policy success with these programs.

Finally, evaluation researchers in the future will need to give greater attention to how program outcomes impact not just adults and couple relationships but child outcomes, as well (Cowan \& Cowan, 2014), because the ultimate justification for public support of CRE programs is that they improve child well-being in disadvantaged families.

\section{References}

*References marked with an asterisk indicate studies included in the meta-analysis.

*Adler-Baeder, F. (2013). Findings for adult participants of marriage and relationship education (MRE) in years 1-5. Retrieved from http://www .alabamamarriage.org/documents/research/ahmreibriefs/adultoverall2013.pdf

*Adler-Baeder, F., Bradford, A., Skuban, E., Lucier-Greer, M., Ketring, S., \& Smith, T. (2010). Demographic predictors of relationship and marriage education participants' pre- and post-program relational and individual functioning. Journal of Couple \& Relationship Therapy, 9, 113 132. http://dx.doi.org/10.1080/15332691003694885

*Adler-Baeder, F., Calligas, A., Skuban, E., Keiley, M., Ketring, S., \& Smith, T. (2013). Linking changes in couple functioning and parenting among couple relationship education participants. Family Relations, 62, 284-297. http://dx.doi.org/10.1111/fare.12006

Allen, K. (2012). I hope: A phenomenological study of the lived experience of fragile families. Marriage \& Family Review, 48, 621-642. http://dx .doi.org/10.1080/01494929.2012.691084

Amato, P. R. (2014). Does social and economic disadvantage moderate the effects of relationship education on unwed couples? An analysis of data from the 15-month Building Strong Families evaluation. Family Relations, 63, 343-355. http://dx.doi.org/10.1111/fare.12069

*Antle, B., Sar, B., Christensen, D., Karam, E., Ellers, F., Barbee, A., \& van Zyl, M. (2013). The impact of the within my reach relationship training on relationship skills and outcomes for low-income individuals. Journal of Marital and Family Therapy, 39, 346-357. http://dx.doi.org/ 10.1111/j.1752-0606.2012.00314.x

Blanchard, V. L., Hawkins, A. J., Baldwin, S. A., \& Fawcett, E. B. (2009). Investigating the effects of marriage and relationship education on couples' communication skills: A meta-analytic study. Journal of Family Psychology, 23, 203-214. http://dx.doi.org/10.1037/a0015211

*Carlson, R. G., Barden, S. M., Daire, A. P., \& Greene, J. (2014). Influence of relationship education on relationship satisfaction for low-income couples. Journal of Counseling \& Development, 92, 418-427. 
"Charles, P., Jones, A., \& Guo, S. (2014). Treatment effects of a relationship-strengthening intervention for economically disadvantaged new parents. Research on Social Work Practice, 0, 1-18.

Cherlin, A. J. (2009). The marriage-go-round: The state of marriage and the family in America today. New York, NY: Knopf.

Cowan, P. A., \& Cowan, C. P. (2014). Conroversies in couple relationship education (CRE): Overlooked evidence and implications for research and policy. [Advance online publication]. Psychology, Public Policy, and Law. Advance online publication. http://dx.doi.org/10.1037/ law0000025

"Cowan, P. A., Cowan, C. P., Pruett, M. K., Pruett, K., \& Gillette, P. (2014). Evaluating a couples group to enhance father involvement in low-income families using a benchmark comparison. Family Relations, 63, 356-370. http://dx.doi.org/10.1111/fare.12072

"Cowan, P. A., Cowan, C. P., Pruett, M. K., Pruett, K., \& Wong, J. J. (2009). Promoting fathers' engagement with children: Preventive interventions for low-income families. Journal of Marriage and Family, 71, 663-679. http://dx.doi.org/10.1111/j.1741-3737.2009.00625.x

${ }^{*}$ Cox, R. B., Jr., \& Shirer, K. A. (2009). Caring for my family: A pilot study of a relationship and marriage education program for low-income unmarried parents. Journal of Couple \& Relationship Therapy, 8, 343-364. http://dx.doi.org/10.1080/15332690903246127

Edin, K., \& Kefalas, M. (2005). Promises I can keep: Why poor women put motherhood before marriage. Berkeley, CA: University of California.

*Einhorn, L., Williams, T., Stanley, S., Wunderlin, N., Markman, H., \& Eason, J. (2008). PREP inside and out: Marriage education for inmates. Family Process, 47, 341-356. http://dx.doi.org/10.1111/j.1545-5300 .2008.00257.x

"Facciglia, A., \& Eisenberg, S. (2009). Administrative report. Weston, FL: PAIRS Foundation.

Fawcett, E. B., Hawkins, A. J., Blanchard, V. L., \& Carroll, J. S. (2010). Do premarital education programs really work? A meta-analytic study. Family Relations, 59, 232-239. http://dx.doi.org/10.1111/j.1741-3729 2010.00598.x

Gueron, J. M., \& Ralston, H. (2013). Fighting for reliable evidence. New York, NY: Russell Sage Foundation.

Halford, W. K., \& Bodenmann, G. (2013). Effects of relationship education on maintenance of couple relationship satisfaction. Clinical Psychology Review, 33, 512-525. http://dx.doi.org/10.1016/j.cpr.2013.02.001

Halford, W. K., \& Van Acker, E. (2012). Are governments and marriage strange bedfellows? Social policy and couple relationship education. In P. Noller \& G. Karantzas (Eds.), Positive pathways for couples and families: Meeting the challenges of relationships (pp. 453-466). New York, NY: Wiley-Blackwell.

*Hall, Y. (2013). Cohabitation effect among Hispanic couples: An appraisal of a relationship education program. (Doctoral dissertation). Available from ProQuest Dissertations and Theses database. (UMI No. 3565757)

Haskins, R., \& Sawhill, I. (2009). Creating an opportunity society. Washington, DC: Brookings Institution.

Hawkins, A. J., Amato, P. R., \& Kinghorn, A. (2013). Are governmentsupported healthy marriage initiatives affective family demographics: A state-level analysis. Family Relations, 62, 501-513. http://dx.doi.org/ 10.1111/fare.12009

Hawkins, A. J., Blanchard, V. L., Baldwin, S. A., \& Fawcett, E. B. (2008). Does marriage and relationship education work? A meta-analytic study. Journal of Consulting and Clinical Psychology, 76, 723-734. http://dx .doi.org/10.1037/a0012584

Hawkins, A. J., \& Fackrell, T. A. (2010). Does relationship and marriage education for lower-income couples work? A meta-analytic study of emerging research. Journal of Couple \& Relationship Therapy, 9, 181191. http://dx.doi.org/10.1080/15332691003694927

Hawkins, A. J., \& Ooms, T. (2012). Can marriage and relationship education be an effective policy tool to help low-income couples form and sustain healthy marriages and relationships? A review of lessons learned. Marriage \& Family Review, 48, 524-554. http://dx.doi.org/10.1080/ 01494929.2012.677751

Hawkins, A. J., Stanley, S. M., Blanchard, V. L., \& Albright, M. (2012). Exploring programmatic moderators of the effectiveness of marriage and relationship education programs: A meta-analytic study. Behavior Therapy, 43, 77-87. http://dx.doi.org/10.1016/j.beth.2010.12.006

Hawkins, A. J., Stanley, S. M., Cowan, P. A., Fincham, F. D., Beach, S. R. H., Cowan, C. P., . . . Daire, A. P. (2013). A more optimistic perspective on government-supported marriage and relationship education programs for lower income couples. American Psychologist, 68, 110-111. http://dx.doi.org/10.1037/a0031792

Hawkins, A. J., \& VanDenBerghe, B. (2014). Facilitating forever: A feasible public policy agenda to help couples form and sustain healthy relationships and enduring marriages. Charlottesville, VA: National Marriage Project.

*Higginbotham, B. J., \& Skogrand, L. (2010). Relationship education with both married and unmarried stepcouples: An exploratory study. Journal of Couple \& Relationship Therapy, 9, 133-148. http://dx.doi.org/10.1080/ 15332691003694893

*Hsueh, J., Alderson, D. P., Lundquist, E., Michalopoulos, C., Gubits, D., Fein, D., \& Knox, V. (2012). The Supporting Healthy Marriage evaluation: Early impacts on low-income families. OPRE Report 2012-11. Washington, DC: Office of Planning, Research, and Evaluation, Administration for Children and Families, U. S. Department of Health and Human Services. http://dx.doi.org/10.2139/ssrn.2030319

Johnson, M. D. (2012). Healthy marriage initiatives: On the need for empiricism in policy implementation. American Psychologist, 67, 296308. http://dx.doi.org/10.1037/a0027743

Kennedy, S., \& Ruggles, S. (2014). Breaking up is hard to count: The rise of divorce in the United States, 1980-2010. Demography, 51, 587-598. http://dx.doi.org/10.1007/s13524-013-0270-9

*Kortla, K., \& Dyer, P. (2013). Hispanic Active Relationships project (HARP). Waco, TX: Baylor School of Social Work.

Lipsey, M. W., \& Wilson, D. B. (2001). Practical meta-analysis. Thousand Oaks, CA: Sage.

"Lowenstein, A. E., Altman, N., Chou, P. M., Faucetta, K., Greeney, A., Gubits, D., . . Nguyen, V. Q. (2014). A family-strengthening program for low-income families: Final impacts from the Supporting Healthy Marriage evaluation, technical Suppl. OPRE Report 2014-09B. Washington, DC: Office of Planning, Research and Evaluation, Administration for Children and Families, U. S. Department of Health and Human Services.

Lucier-Greer, M., \& Adler-Baeder, F. (2012). Does couple and relationship education work for individuals in stepfamilies? A meta-analytic study. Family Relations, 61, 756-769. http://dx.doi.org/10.1111/j.1741-3729 2012.00728.x

*Lundquist, E., Hsueh, J., Lowenstein, A., Faucetta, K., Gubits, D., Michalopoulos, C., \& Knox, V. (2014). A family-strengthening program for low-income families: Final impacts from the Supporting Healthy Marriage evaluation. OPRE Report 2013-49A. Washington, DC: Office of Planning, Research and Evaluation, Administration for Children and Families, U. S. Department of Health and Human Services.

McAllister, S., Duncan, S. F., \& Hawkins, A. J. (2012). Examining the early evidence for self-directed marriage and relationship education: A meta-analytic study. Family Relations, 61, 742-755. http://dx.doi.org/ 10.1111/j.1741-3729.2012.00736.x

McLanahan, S., \& Beck, A. N. (2010). Parental relationships in fragile families. The Future of Children, 20, 17-37. http://dx.doi.org/10.1353/ foc. 2010.0007

*Mitchell, A., \& Owen, J. (in press). Family stress model and relationship education: The importance of racial/ethnic minority couples' dyadic coping. Journal of Family Therapy. 
Nowak, C., \& Heinrichs, N. (2008). A comprehensive meta-analysis of Triple P-Positive Parenting Program using hierarchical linear modeling: Effectiveness and moderating variables. Clinical Child and Family Psychology Review, 11, 114-144. http://dx.doi.org/10.1007/s10567-0080033-0

*O'Halloran, M. S., Rizzolo, S., Cohen, M. L., \& Wacker, R. (2013). Assessing the impact of a multiyear marriage education program. The Family Journal, 21, 328-334. http://dx.doi.org/10.1177/1066 480713476849

Orr, L. (1999). Social experiments: Evaluating public programs with experimental methods. Thousand Oaks, CA: Sage.

*Owen, J., \& Antle, B. (2014). Individual relationship education program as primary prevention for intimate partner violence. Manuscript under review.

*Owen, J., Antle, B., \& Barbee, A. (2013). Alliance and group cohesion in relationship education. Family Process, 52, 465-476. http://dx.doi.org/ 10.1111/famp.12039

*Owen, J., Quirk, K., Bergen, C., Inch, L. J., \& France, T. (2012). The effectiveness of PREP with lower-income racial/ethnic minority couples. Journal of Marital and Family Therapy, 38 (Suppl. 1), 296-307. http:// dx.doi.org/10.1111/j.1752-0606.2012.00294.x

Pinquart, M., \& Teubert, D. (2010). A meta-analytic study of couple interventions during the transition to parenthood. Family Relations, 59, 221-231. http://dx.doi.org/10.1111/j.1741-3729.2010.00597.x

Rauer, A. J., Adler-Baeder, F., Lucier-Greer, M., Skuban, E., Ketring, S. A., \& Smith, T. (2014). Exploring processes of change in couple relationship education: Predictors of change in relationship quality. Journal of Family Psychology, 28, 65-76. http://dx.doi.org/10.1037/ a0035502

Rhoades, G. K., Stanley, S. M., \& Markman, H. J. (2012). The impact of the transition to cohabitation on relationship functioning: Crosssectional and longitudinal findings. Journal of Family Psychology, 26, 348-358. http://dx.doi.org/10.1037/a0028316

*Rienks, S. L., Wadsworth, M. E., Markman, H. J., Einhorn, L., \& Etter, E. M. (2011). Father involvement in urban low-income fathers: Baseline associations and changes resulting from preventive intervention. Family Relations, 60, 191-204. http://dx.doi.org/10.1111/j.1741-3729.2010 $.00642 . \mathrm{x}$

*Shamblen, S. R., Arnold, B. B., McKiernan, P., Collins, D. A., \& Strader, T. N. (2013). Applying the creating lasting family connections marriage enhancement program to marriages affected by prison reentry. Family Process, 52, 477-498. http://dx.doi.org/10.1111/famp.12003

"Stanley, S. M., Allen, E. S., Markman, H. J., Saiz, C. C., Bloomstrom, G., Thomas, R., . . Bailey, A. E. (2005). Dissemination and evaluation of marriage education in the Army. Family Process, 44, 187-201. http:// dx.doi.org/10.1111/j.1545-5300.2005.00053.x
*Stanley, S. M., Rhoades, G. K., Loew, B. A., Allen, E. S., Carter, S., Osborne, L. J., . . Markman, H. J. (2014). A randomized controlled trial of relationship education in the U.S. Army: 2-year outcomes. Family Relations, 63, 482-495. http://dx.doi.org/10.1111/fare.12083

Stanley, S. M., Rhoades, G. K., \& Whitton, S. W. (2010). Commitment: Functions, formation, and the securing of romantic attachment. Journal of Family Theory and Review, 2, 243-257. http://dx.doi.org/10.1111/j .1756-2589.2010.00060.x

Trail, T. E., \& Karney, B. R. (2012). What's (not) wrong with low-income marriages. Journal of Marriage and Family, 74, 413-427. http://dx.doi .org/10.1111/j.1741-3737.2012.00977.x

*VanderWal, C., \& Manning, W. (2008). Healthy marriage, healthy relationship, Grand Rapids: Administrative report. Grand Rapids, MI: Healthy Marriages, Healthy Relationships.

*Wadsworth, M. E., Santiago, C. D., Einhorn, L., Etter, E. M., Rienks, S., \& Markman, H. (2011). Preliminary efficacy of an intervention to reduce psychosocial stress and improve coping in low-income families. American Journal of Community Psychology, 48, 257-271. http://dx.doi.org/ 10.1007/s10464-010-9384-Z

"Wilde, J. L., \& Doherty, W. J. (2013). Outcomes of an intensive couple relationship education program with fragile families. Family Process, 52, 455-464. http://dx.doi.org/10.1111/famp.12012

Wildsmith, E., Steward-Streng, N. R., \& Manlove, J. (2011). Childbearing outside of marriage: Estimates and trends in the United States. Child Trends Research Brief, \#2011-29. Washington, DC: Child Trends.

Williamson, H. C., Trail, T. E., Bradbury, T. N., \& Karney, B. R. (2014). Does premarital education decrease or increase couples' later helpseeking? Journal of Family Psychology, 28, 112-117. http://dx.doi.org/ 10.1037/a0034984

Wood, R. G., Moore, Q., Clarkwest, A., \& Killewald, A. (2014). The long-term effects of Building Strong Families: A program for unmarried parents. Journal of Marriage and Family, 76, 446-463. http://dx.doi .org/10.1111/jomf.12094

"Wood, R. G., Moore, Q., Clarkwest, A., Killewald, A., \& Monahan, S. (2012). The long-term effects of Building Strong Families: A relationship skills education program for unmarried parents, OPRE Report \#2012-28A. Washington, DC: Office of Planning, Research, and Evaluation, Administration for Children and Families, U.S. Department of Health and Human Services. Retrieved from http://www.acf.hhs.gov/ programs/opre/index.html

Received May 9, 2014

Revision received October 10, 2014 Accepted October 25, 2014 


\section{Correction to Hawkins and Erickson (2015)}

In the article "Is Couple and Relationship Education Effective for Lower Income Participants? A Meta-Analytic Study," by Alan J. Hawkins and Sage E. Erickson (Journal of Family Psychology, 2015, Vol. 29, No. 1, pp. 59-68. http://dx.doi.org/10.1037/fam0000045), the link to supplemental materials (http://dx.doi.org/10.1037/fam0000045.supp) was inadvertently omitted. All versions of this article have been corrected.

http://dx.doi.org/10.1037/fam0000114 